\title{
Chemical pleurodesis in malignant pleural effusions: a randomised prospective study of mepacrine versus bleomycin
}

\author{
Stein Koldsland, Jan L Svennevig, Gustav Lehne, Egil Johnson
}

\begin{abstract}
Background-The treatment of recurrent pleural effusion in advanced malignant disease should be efficient and with tolerable side effects. Since 1983 intrathoracic instillation of the antimalaria drug mepacrine has been used to achieve pleurodesis. The cytotoxic drug bleomycin has been claimed to be equally effective and with fewer side effects. The present study was designed to compare these two agents.

Methods-Forty patients with carcinoma and pleural effusions refractory to repeated pleural aspirations over the previous 12 weeks were randomised to receive treatment with intrathoracic instillation of mepacrine or bleomycin. Fluid volumes before and after pleurodesis, drainage time, and side effects were registered and analysed, and the response to treatment was evaluated by clinical examination and chest radiography.

Results-The amount of fluid produced after treatment in the patients receiving mepacrine was lower than in those receiving bleomycin, and the duration of chest drainage was shorter. After $\mathbf{3 0}$ days 16 of 20 in the mepacrine group responded to treatment and 10 of 20 in the bleomycin group. Most patients died during the three months observation period. Moderate side effects occurred equally in both groups.

Conclusions-Chemical pleurodesis can reduce or stop pleural effusion in many patients, and in this study mepacrine appeared to be more efficient than bleomycin. A prospective study with a larger number of patients is now warranted.
\end{abstract}

(Thorax 1993;48:790-793)

Pleural effusion occurs in many advanced malignant diseases and often leads to dyspnoea and the discomfort of repeated thoracocenteses. Several different chemical agents have been instilled into the pleural cavity to achieve a sterile inflammation and adherence between the visceral and the parietal pleura with obliteration of the pleural space. At Ullevaal Hospital the antimalaria drug mepacrine has been used for chemical pleurodesis since $1983 .{ }^{1}$ Severe pleuritic pain, hallucinations, and convulsions following the administration of mepacrine have been reported by some workers. ${ }^{23}$ The cytotoxic drug bleomycin has been claimed to be equally efficient and with fewer side effects than mepacrine ${ }^{45}$ but a randomised comparative study has never been carried out. The present study was undertaken to compare these two agents.

\section{Methods}

\section{PATIENTS}

Forty consecutive patients with malignant pleural effusion entered a prospective randomised trial. The patients were mostly admitted from the oncological department of our hospital. Twenty patients were treated with mepacrine and 20 with bleomycin; 39 patients had histologically proven disseminated carcinoma, lymphoma or mesothelioma with a pleural effusion, and one had a pleural effusion with malignant cells of unknown origin. Positive cytological or histological test results were obtained from the pleura or fluid in 16 of the 40 patients (table 1). All patients had been treated with repeated needle aspirations before entering the study (table 2) and no patient had undergone previous pleurodesis with other agents. Patients with renal failure and those needing continuous oxygen therapy were excluded because about $45 \%$ of intrapleural bleomycin is absorbed ${ }^{6}$ and could exert toxic effects on the lung, particularly if renal elimination was impaired and when $O$ bleomycin is combined with oxygen. ${ }^{78}$ Only patients thought by their supervising physi- ${ }^{\circ}$ cian to have a life expectancy of more than a

Table 1 Patient details

\begin{tabular}{lll}
\hline & Mepacrine & Bleomycin \\
\hline Number of patients & 20 & 20 \\
Women/men. & $14 / 6$ & $13 / 7$ \\
Median (range) age (years) & $67(38-85)$ & $70(43-80)$ \\
Breast cancer & 8 & 8 \\
Bronchial cancer & 3 & 6 \\
Ovarian cancer & 2 & 2 \\
Mesothelioma & 4 & 0 \\
Other cancer & 3 & 4 \\
Positive cytology & 4 & 6 \\
Positive pleural biopsy & 4 & 2 \\
Negative cytology or biopsy & 2 & 4 \\
Pleural fluid not examined & 10 & 8 \\
\hline
\end{tabular}


Table 2 Median (range) interval between diagnosis and treatment, fluid production, and duration of drainage before pleurodesis

\begin{tabular}{lll}
\hline & Mepacrine & Bleomycin \\
\hline $\begin{array}{l}\text { Interval between diagnosis and } \\
\quad \text { treatment (months) }\end{array}$ & $3(0-13)$ & $3(1-9)$ \\
$\begin{array}{l}\text { Number of thoracocenteses } \\
\text { in the last } 3 \text { months }\end{array}$ & $2 \cdot 5(1-5)$ & $3 \cdot 0(2-7)$ \\
$\begin{array}{l}\text { Total amounts of fluid by } \\
\text { thoracocentesis in the }\end{array}$ & $2100(900-15300)$ & $3150(1000-8150)$ \\
$\begin{array}{l}\text { last } 3 \text { months (ml) } \\
\quad \text { drainage before pleurodesis (ml) }\end{array}$ & $2595(855-7040)$ & $2292(1050-5585)$ \\
$\begin{array}{l}\text { Drainage time before pleurodesis (days) } \\
\text { Amounts of fluid drained in the last }\end{array}$ & $6(3-14)$ & $5 \cdot 5(2-20)$ \\
$\quad 24$ hours before pleurodesis (ml) & $97 \cdot 5(0-320)$ & $80(0-355)$ \\
\hline
\end{tabular}

All differences not significant.
Table 3 Median (range) fluid production, duration of chest drainage, and body temperature after pleurodesis

\begin{tabular}{lll}
\hline & Mepacrine & Bleomycin \\
\hline $\begin{array}{c}\text { Total amounts } \\
\text { of fluid (ml) }\end{array}$ & $87.5(5-1250)$ & $395(0-8225)$ \\
$\begin{array}{c}\text { Duration of chest } \\
\text { drainage (days) }\end{array}$ & $2(1-10)$ & $4(1-21)$ \\
$\begin{array}{c}\text { Temperature last day } \\
\text { before pleurodesis }\left({ }^{\circ} \mathrm{C}\right)\end{array}$ & $37(35-38)$ & $37(35-38)$ \\
$\begin{array}{c}\text { Temperature first day } \\
\text { after pleurodesis }\left({ }^{\circ} \mathrm{C}\right)\end{array}$ & $38(36-39 \cdot 5)$ & $38(36-39)$ \\
$\begin{array}{c}\text { Duration of fever (days) } \\
{ }^{\star} \mathrm{p}<0.05 ;{ }^{\star \star} \mathrm{p}<0.001 .\end{array}$ & $1(0-8)$ & $1(0-5)$ \\
\hline
\end{tabular}

the two groups. For discrete variables the $\chi^{2}$ or Fisher's exact test were used. Values below 0.05 were considered significant.

month were included. In general the two groups of patients were comparable (tables 1 and 2).

Informed consent was obtained from all patients before inclusion in the study and the protocol was approved by the local ethics committee.

\section{PLEURODESIS}

Before treatment a 28 or 32 Fr chest tube was inserted into the lower pleural cavity through the middle or anterior axillary line under local anaesthesia. Suction of $15 \mathrm{~mm} \mathrm{H}_{2} \mathrm{O}$ was maintained until fluid production was reduced to about $100 \mathrm{ml} /$ day and chest radiographs showed a dry pleural cavity. Only two patients were included in the study with fluid production greater than $100 \mathrm{ml} /$ day (320 and $355 \mathrm{ml} /$ day). The tube was clamped close to the thoracic wall and the sclerosing agent was injected through a small cannula directly into the tube. We used $800 \mathrm{mg}$ mepacrine diluted in $20 \mathrm{ml}$ saline or $60 \mathrm{mg}$ bleomycin in $100 \mathrm{ml}$ saline. The patients were then turned from side to side for two hours to ensure optimal exposure of the substance to all parts of the pleural space. In the mepacrine group suction was re-established after two hours according to our hospital protocol, while in the bleomycin group suction was re-established the next day according to the procedure of Paladine and coworkers. ${ }^{5}$

Following the instillation fluid production initially increased as a result of the inflammatory response. The chest tube was removed when it had reduced to $100 \mathrm{ml} /$ day or less. Patients with sustained volumes of more than $200 \mathrm{ml} /$ day after the pleurodesis were considered to be primary therapy failures. These patients were offered treatment with the alternative agent. Possible effects of the second instillation were not evaluated.

The patients were followed up with chest radiographs monthly for three months. The response was classified as: (1) no reaccumulation of fluid; (2) small amounts of fluid reaccumulation with no or mild symptoms; and (3) reaccumulation of fluid with severe dyspnoea needing thoracocentesis (failure). for comparison of the continual variables in

\section{Results}

The numbers in each histological group were small and the patients with mesothelioma and bronchial carcinoma were particularly unevenly distributed. The time between diagnosis of the effusion and the pleurodesis was the same in both groups, and there were no significant differences in the number of thoracocenteses, the duration of drainage, or the volumes of fluid drained before the pleurodesis.

After pleurodesis the median drainage time was significantly longer in the bleomycin group, and the total amount of drained fluid was more than four times higher than in the mepacrine group (table 3 ).

Primary therapy failure occurred in four cases in the bleomycin group (two breast cancer, one ovarian cancer, one non-Hodgkin's lymphoma). All these patients responded well to a second treatment with mepacrine, although they were evaluated as failure after 30 days according to the protocol. In one patient with oesophageal carcinoma the effusion was resistant to treatment with both agents and drainage was maintained until death 21 days later.

Thirty six patients were evaluable one month after the pleurodesis. Sixteen of the 20 patients in the mepacrine group had responded and 10 of the 20 in the bleomycin group (table 4). Evaluation after this time was not possible because many of the patients died during the observation time.

Median survival time after pleurodesis was

Table 4 Evaluation one month after pleurodesis

\begin{tabular}{lcc}
\hline & Mepacrine & Bleomycin \\
\hline $\begin{array}{l}\text { No recurrence } \\
\begin{array}{l}\text { Small recurrence } \\
\text { not needing } \\
\text { thoracocentesis }\end{array}\end{array}$ & 11 & 8 \\
$\begin{array}{l}\text { Total responders } \\
\text { Recurrence needing }\end{array}$ & 5 & 2 \\
$\quad$ thoracocentesis & 16 & 10 \\
Not recorded or dead & 2 & $8 \dagger$ \\
\hline
\end{tabular}

${ }^{\star} \mathrm{NS} ;{ }^{\star \star} \mathrm{p}<0.05$

†Including four primary failures who responded well to a second instillation of mepacrine. 
two months $(0-7)$ in the mepacrine group and 3.5 months $(0-22)$ in the bleomycin group (NS). The respective median survival times from diagnosis was six months (2-16) and seven months (2-23), respectively (NS). Only six patients were alive 12 months after the diagnosis.

SIDE EFFECTS (table 3)

There were no differences in the incidence of side effects between the treatment groups. Sixteen patients treated with mepacrine and 13 with bleomycin suffered from chest pain the day after instillation, mostly controllable with paracetamol although four patients in each group needed opiates. For most the pain ceased after one day as judged by the use of analgesics and by bed side questioning. Fourteen patients in the mepacrine group and 11 in the bleomycin group had an elevation of body temperature to $38-39^{\circ} \mathrm{C}$ lasting for one day. In one patient with a lymphoma and another with a bronchial carcinoma a combination of hyperventilation, hypotension, tachycardia, and anxiety occurred immediately after instillation of bleomycin. These two patients were treated with opiates and oxygen and the symptoms disappeared quickly. No other serious side effects were recorded. There was no case of CNS toxicity and no pneumothoraces occurred.

\section{Discussion}

The prognosis for patients with malignant pleural effusion is very poor, with only $10-15 \%$ being alive after one year, ${ }^{9}$ and is probably best in breast cancer and bronchial carcinoma. ${ }^{9}$ Our patients came to pleurodesis a median 2.3 months after the diagnosis of pleural effusion (table 2). This rather long time might explain some of the short survival times after pleurodesis. Such patients are uncomfortable with dyspnoea and pain, and repeated thoracocenteses are often necessary. The cause of the effusion is either obstruction of lymphatics by tumour infiltration in the lung or mediastinum, or direct infiltration by tumour tissue into the pleural cavity. The fluid usually rapidly recurs after thoracocentesis.

Chemical pleurodesis is a palliative treatment aiming at an obliteration of the pleural space. The effect of mepacrine at a cellular level is not known, but it induces a chemical pleuritis which causes adhesions and obliteration of the pleural space. Bleomycin inhibits DNA and protein synthesis, but pleurodesis is believed to result from a separate inflammatory response with secondary fibrosis. A local cytotoxic effect may contribute to the mechanism of action, as suggested by the fact that effusions in patients with primary tumours responsive to systemic bleomycin often respond to intrapleural treatment with this drug. ${ }^{10}$

A number of sclerosing agents have been used in the treatment of pleural effusions with various methods of administration. Any attempt to rank the agents according to effect and side effects could be misleading because of the scarcity of controlled clinical trials. Three prospective clinical trials with mepacrine and bleomycin have been published but none have compared the two agents with each other. ${ }^{61112}$ In two studies, of 20 and 34 patients respectively, both mepacrine and bleomycin were found as effective as tetracycline in preventing reaccumulation of malignant pleural effusions. ${ }^{112}$ Our results 30 days after pleurodesis indicated an $80 \%$ response to mepacrine, as expected, ${ }^{13}$ and a $50 \%$ response to bleomycin, which was lower than that reported by others. ${ }^{13}$

The two methods we used for intracavitary treatment were not entirely the same as the drain clamping time was two hours after mepacrine and 24 hours after bleomycin, and the solution volumes were 20 and $100 \mathrm{ml}$, respectively. This could have influenced the results but, if drainage time is calculated from the end of the clamping period, the difference in volumes drained is still significant but the difference in drainage time is not.

Instillation of sclerosing agents into the pleural cavity has been associated with numerous, and often serious, side effects. ${ }^{14}$ In our study the side effects were moderate with no statistical difference between the two agents. According to Bayly and coworkers fever was more common with mepacrine than with tetracycline, ${ }^{12}$ whereas the pyrogenic effect of bleomycin was similar to that of tetracycline in another randomised trial. ${ }^{11}$ In our study mepacrine seemed less toxic than previously reported, ${ }^{3}$ including a moderate fever of short duration and moderate chest pain the day after the instillation. Fever was more common with bleomycin in our study than described elsewhere. ${ }^{45}$

Serious toxic effects were not seen in our study, although two brief episodes of hypotension were seen after bleomycin instillation. Similar reactions have been recorded with mepacrine. ${ }^{3} \mathrm{~A}$ few cases of sudden fatal reactions to intrapleural instillation of mepacrine and bleomycin have been reported. ${ }^{2315}$ High serum levels of the drug probably increase the risk of fatal reactions. Therefore, not only the instilled dose but also the duration of drug exposure in the pleural cavity may contribute to the risk of systemic complications. One should keep in mind that the cerebrocortical stimulant effect of mepacrine may cause life threatening convulsions, whereas the pulmonary toxic effect of bleomycin may be fatal even at low systemic doses. ${ }^{16}$

This study shows that chemical pleurodesis with mepacrine produces a better immediate inhibition of fluid (table 3 ) and fewer primary treatment failures than bleomycin. These results support the call for a larger prospective study comparing these two agents in patients with histologically or cytologically confirmed malignant pleural effusions.

1 Övrum E, Pillgram-Larsen J. Treatment of malignant pleural effusions with mepacrine chloride. Tidsskr Nor Laegeforen 1983;103:1009-11 (in Norwegian with English abstract) 
2 Borda I, Krant M. Convulsions following intrapleural administration of quinacrine hydrochloride. $¥ A M A$ 1967;210:173-4.

3 Borja ER, Pugh R. Single dose quinacrine (atabrine) and thoracostomy in the control of pleural effusions in patients with neoplastic diseases. Cancer 1973;31: 899-902.

4 Ostrowski MJ, Priestman TJ, Houston RF, Martin WMC. A randomized trial of intracavitary bleomycin and Corynebacterium parvum in the control of malignant pleural effusions. Radiother Oncol 1989;14:19-26.

5 Paladine W, Cunningham TJ, Sponzo R, Donavan M, Olson $\mathrm{K}$, Horton J. Intracavitary bleomycin in the management of malignant effusions. Cancer 1976;38: agement

6 Alberts DS, Chen HSG, Mayersohn M, Perrier D, Moon TE, Gross JF. Bleomycin pharmacokinetics in man II: Intracavitary administration. Cancer Chemother Pharmacol 1979;2:127-32.

7 Lehne G, Lote K. Pulmonary toxicity of cytotoxic and immunosuppressive agents. A review. Acta Oncol 1990;29:113-24.

8 Siegel RD, Schiffman FJ. Systemic toxicity following intracavitary administration of bleomycin. Chest 1990; 98:507.
9 Yamada S, Takeda T, Matsumoto K. Prognostic analysis of malignant pleural and peritoneal effusions. Cancer 1983;51:136-40.

10 Ostrowski MJ, Halsall GM. Intracavitary bleomycin in the management of malignant effusions: a multicenter study. Cancer Treat Rep 1982;66:1903-7.

11 Kessinger A, Wigton RS. Intracavitary bleomycin and tetracycline in the management of malignant pleural effusions: a randomized study. F Surg Oncol 1987;36: 81-3.

12 Bayly TC, Kisner DL, Sybert A, Macdonald JS, Tsou E Schein PS. Tetracycline and quinacrine in the control of malignant pleural effusions: a randomized trial. Cancer 1978;41:1188-92.

13 Ruckdeschel JC. Management of malignant pleura effusion: an overview. Semin Oncol 1988;15(Suppl 3): 24-8.

14 Friedman MA, Slater E. Malignant pleural effusions. Cancer Treat Rev 1978;5:49-66.

15 Trotter JM, Stuart JFB, McBeth F, McVie JG, Calman KC. The management of malignant effusions with bleomycin. Br f Cancer 1979;40:310 A

16 Levy RL, Chiarillo S. Hyperpyrexia, allergic-type response and death occurring with low-dose bleomycin administration. Oncology 1980;37:316-7. 